\title{
Challenges in Monitoring Metallic Pipeline Corrosion Using Ultrasonic Waves - A Review Article
}

\author{
R.N.P. Gunarathna and V. Sivahar
}

\begin{abstract}
Corrosion is a widespread problem in metallic pipelines. Copious use of pipelines across many industries urges the application of inspection technologies for early detection of corrosion in order to prevent its costly and fatal outcomes. As of today, there is a range of ultrasonic techniques that cater to finding and sizing of the extent of corrosion. For piping inspection, guided wave (GW) modes are of interest for detecting corrosion defects as they offer rapid scanning over extended distances. Over the past three decades, the use of GWs have progressed tremendously and are commonplace today. More complex testing units have been fabricated because of recent advances in the fields of smart materials, electronics, and communication technologies. However, GW signals contain multiple modes and only a handful of them are used in inspection. This paper aims to provide an overview of current GW approaches focused on the detection, localization, and evaluation of corrosion defects in pipelines. The study presents a literature review of the main issues encountered in pipeline systems when using GWs and recent attempts to overcome the barriers.
\end{abstract}

Keywords: Corrosion, Guided Waves, Metallic Pipelines

\section{Introduction}

Metallic pipes mostly fabricated from carbon steel and low alloy steel grade are essential components in the infrastructure of petroleum and chemical industries. These pipelines transport fluids that are often hot, pressurized, caustic, and flammable under harsh environmental conditions making them susceptible to severe corrosion. Under dry conditions, corrosion proceeds slowly, converting metal ions into more stable oxides. In the presence of moisture, microbes, stress, sour gas and salts, the rate of corrosion accelerates. Dissimilar metals within the piping system, high operating temperature, and turbulent flow rates of the fluids and gases also contribute to corrosion [1-3]. Corrosion occurs in many forms at different locations in pipes. Standard terminologies, definitions, and acronyms are used by corrosion professionals to explain these mechanisms [4-6]. Overall, the outcomes of corrosion in pipelines are wall thinning, localized metal loss, and scale deposition. Wall thinning results from uniform corrosion while localized corrosion is generated from pitting, crevice corrosion, and intergranular corrosion. Localized metal loss in pipelines can be clustered or in isolated patterns. Often, these forms of corrosion occur behind visible surfaces. Corrosion affects material health thereby reducing the durability and service life of the pipeline systems. In retrospect, it has caused disastrous ruptures in pipeline systems [7-9]. Further, production interruptions due to failures incur huge monetary losses to companies. Therefore, industries are keen on establishing inspection systems that closely monitor pipes for early detection of corrosion.

Ultrasonic waves have been in practical usage for defect detection since 1942 [10]. The use of ultrasonic waves does not impair the function of the test subject unlike $x$-rays or gamma rays, and there are no known validated potential health hazards to the personnel. For ultrasonic testing (UT), sound waves above $20 \mathrm{kHz}$ are employed to make measurements. Because of its capability of flaw detection, evaluation, and material characterization, UT is very much valued as a corrosion inspection technique. Ultrasonic methods are non-intrusive which offer the advantage of monitoring corrosion without inserting a retrievable probe into the process stream. Thus, it is employed in in-line inspection (ILI) to avoid unnecessary possible shutdowns [11-13]. Ultrasonic waves used for corrosion inspection fall into two categories as bulk waves and GWs.

Eng. (Miss) R.N.P. Gunarathna, B.Sc. Eng. (Hons) (Moratuwa), Certified NDT Inspector Level II (ASNT (USA))

Email:gunarathnarnp@gmail.com

ORCID ID : https://orcid.org/0000-0003-3085-3867

Mr. V. Sivahar, B.Sc. Eng. (Hons) (Moratuwa), M.Phil. (Moratuwa),

Senior Lecturer in the Department of Materials Science and

Engineering, University of Moratuwa.

Email:vsivahar@uom.lk

ORCID ID : https://orcid.org/0000-0003-3160-2760 
Bulk waves only have two modes: longitudinal and shear. They are relatively easier to handle and typically used to inspect areas closer to the transducer. Inspection and data analysis methods of bulk wave techniques are efficiently applied by experts in the field [14-16]. As opposed to bulk waves, GWs require the aid of a boundary for propagation. GWs entail from the superposition of bulk, longitudinal and shear waves. The various oscillatory patterns generated upon wave encounter with boundaries (surfaces and interfaces) enable long-distance wave propagation within the structure. For piping systems, point-by-point bulk wave measurements can be timeconsuming and costly. To minimize costs and save time, inspections of randomly chosen positions are often performed. For pipework inspection, GWs are preferred as they offer rapid scanning methods, volumetric coverage for long lengths of pipelines for corrosion defects. For pipe inspection, a whole class of GWs is used. Currently established GW methods offer inspection lengths up to about 100 meters from a single transducer position [17-19].

\subsection{Ultrasonic Testing}

A standard UT inspection system includes several units, such as a pulser-receiver, transducer, and display monitors. A pulserreceiver is an intricate electronic circuit designed to generate the energy that drives the transducer within an ultrasonic measuring system. The pulser-receiver also amplifies and/or filters the receiving transducer's electrical response. The ultrasonic transducers transform electrical pulses into acoustic pulses, and vice-versa. The transducer is placed on the test object to transmit an ultrasonic soundwave through the test medium. The GW systems use multiple annular arrays of transducers permanently or periodically clamped on the pipe circumference at the ends of the pipe section (Fig. 1). Ultrasonic waves pass from one ring to the other within the pipe wall and the time difference between the transmitted and receipt waves is measured. This time is calibrated against the boundaries to be evaluated.

Ultrasonic waves are directional. Upon an encounter with an abrupt geometry change (defect) the ultrasonic waves are scattered. The differential time of arrival of various scattered waves, the change of amplitude, phase, direction transmitted signal upon scattering provide details about the size, location, orientation, and other characteristics of defects. The two instrument arrangements of collecting the ultrasonic waveform are called reflection (or pulse-echo) and attenuation (or throughtransmission). In reflection (or pulse-echo) mode, the transducer performs both the sending and the receiving of the ultrasonic waves. The arrival time of the reflection encodes the distance to the defect. In attenuation (or through-transmission) mode, one transducer transmits ultrasound through one surface, and a separate transducer on another surface catches the signal. The reduction or the loss of the sound transmitted exposes the existence of defects or other imperfections in the space between the transmitter and receiver. GWs excited along a pipe is detected using both pulse-echo and attenuation modes [20-22].

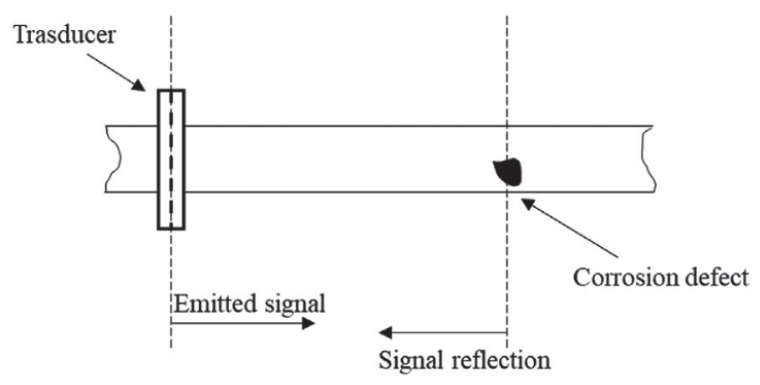

Figure 1 - Ultrasonic Waves Emitted by the Transducers Upon an Encounter with a Defect on the Pipe Walls are Reflected and Returned

\subsection{Transducers}

The two available types of commercial LRUT (Long Range Ultrasonic Testing) rings are composed of piezoelectric transducers (PZT) and electromagnetic acoustic transducers (EMAT). As opposed to EMATs, PZTs were the first transducers used in UT. A piezoelectric transducer contains piezoelectric elements which generates ultrasound pulses as response to an applied electric field. The most widely used piezoelectric materials for UT transducers are lead- zirconate-titanate (PZT) and Barium Titanate. The major limitation of PZTs in field inspection is the need for a couplant [23].

In literature, many variations of EMATs exist. Nonetheless, in all of them, the underlying mechanism to generate and detect sound waves is through magnetic field interaction. For conductive materials, EMATs relying on the Lorentz force mechanism are used [24]. Regarding a ferromagnetic material, an applied magnetic field induces magnetostriction along with the Lorentz force, but magnetostriction is 
the principal mechanism of ultrasonic wave transduction [25-27]. Such transducers are called magnetostrictive sensors (MsS).

\section{Theoretical background}

\subsection{Fundamentals of Guided Wave Propagation in Cylindrical Structures}

Considering an isotropic elastic medium, the governing equation for the propagation of stress waves is Navier's equation of motion which can be given in a vector form as, $\mu \nabla^{2} u+(\lambda+\mu) \nabla(\nabla . u)=\rho\left(\partial^{2} u / \partial t^{2}\right)$

where $u$ is the displacement vector, $\nabla^{2}$ is the three-dimensional Laplace operator, $\mu$ and $\lambda$ are Lame's constants, $\rho$ is the density, and $t$ is the time. To simplify the problem using Helmholtz's decomposition, the displacement vector in Eq. (1) can be expressed as a sum of the gradient of a scalar potential field, $\phi$, and the curl of a vector potential field, $\psi$ :

$u=\nabla \phi+\nabla \times \psi$

Substituting Eq. (2) into Eq. (1), along with $\nabla \cdot \psi=$ 0 , yields the standard wave equations describing longitudinal and shear propagation, respectively:

$C_{L^{2}} \nabla^{2} \phi=\partial^{2} \phi / \partial t^{2}$

$C S^{2} \nabla^{2} \psi=\partial^{2} \psi / \partial t^{2}$

where $C_{L}=\sqrt{ }(\lambda+\mu) / \rho$ and $C_{S}=\sqrt{\mu} \mu / \rho$ are the longitudinal and shear velocities, respectively. From Eqs. (3) and (4), solutions of all elastic wave modes propagating in a structure can be obtained when relevant boundary conditions are given. For an infinitely extended homogeneous hollow cylinder with its axis along the $\mathrm{z}$-coordinate of a cylindrical system (r; $\theta ; \mathrm{z}$ ) (Fig. 2), it follows that, to satisfy Eqs. (3) and (4), Bessel functions of the first and second kind must be introduced into the scalar potential and the three vector potential components. Assuming harmonic wave propagation, and provided that traction-free boundary conditions on both the external and internal surfaces of the hollow cylinder are met, the components of the displacement vector $\left(U_{r}, U_{\theta}, U_{z}\right)$ can be then obtained in terms of the potentials from Eq. (2) [28] [29].

For an anisotropic cylinder hollow pipe, the roots of Eq. (1) result as follows.

$U_{r}=U_{r}(r) \cos (n \theta) \cos (\omega t+\varsigma z)$

$U_{\theta}=U_{\theta}(r) \cos (n \theta) \cos (\omega t+\varsigma z)$

$U_{z}=U_{z}(r) \cos (n \theta) \cos (\omega t+\varsigma z)$

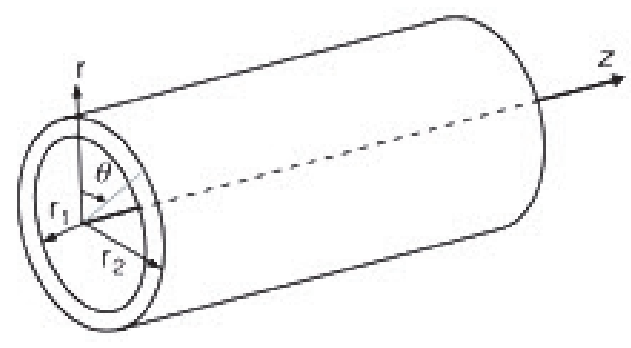

Figure 2 - Reference Coordinates and Dimensions

$U_{r}, U_{\theta}$, and $U_{z}$ are amplitudes expressed using Bessel functions. Upon solving the last three equations for each of the displacement components, and applying the boundary conditions on each of the two free surfaces, results in six unknown constants in total. Setting the determinant of these six equations to zero yields the dispersion relation (phase and group velocities against frequency) which can be solved using numerical techniques. Hence, the evaluation of elastic wave propagation in steel pipes has been conducted both numerically and experimentally [30] [31].

\subsection{Mode Types and Nomenclature}

The three basic modes of GW that exist in hollow cylinders are longitudinal $(L)$, torsional $(T)$, and flexural (F). For longitudinal modes, their axial ( $z$ ) and radial $(r)$ displacement components are non-zero whereas their angular displacement $(\theta)$ is zero. The displacement components of torsional modes are the very opposite of that (Fig. 3). Within each wave category, many number of modes exist. For convenience, a dual index system introduced by Silk and Bainton is employed to denote these modes [32]. The modes are labeled $L(0, m)$, $T(0, m)$, and $F(n, m)$ where $m$ and $n$ are positive integers, and $L, T$, and $F$ represent longitudinal, torsional, and flexural type modes, respectively. The integers $m$ and $n$ designate the circumferential order of a mode and the group order of a mode, correspondingly. Since longitudinal and torsional waves are axisymmetric, their circumferential number $(m)$ is zero. According to the distribution of the wave energy along the circumferential direction, the flexural wave modes contain nonaxisymmetric and axisymmetric modes. For example, axisymmetric $L(0,2)$ has predominantly axial displacement and the $L(0,1)$ has both axial and radial displacement. The oscillation patterns of the $L(0,2)$ and $T(0,1)$ mode guided waves are shown in Fig. 3 , in 
which the oscillation direction of $L(0,2)$ is parallel to its propagation direction, but for $T(0,1)$ mode, the oscillation direction is perpendicular to the propagation.

The number of modes present at a given frequency in a solid waveguide (geometrical structure capable of propagating energy in a preferred direction) is dependent on the radius of the waveguide. In a hollow cylinder, the critical dimensions are the wall thickness and the ratio of the external to internal wall diameter [33]. Practically, these wave modes are operated in the frequency range of $20-100 \mathrm{kHz}$ and called LRUT. Theoretically, for shallow cylindrical shells, the longitudinal modes approach the Lamb wave modes, whereas the torsional modes approach the Shear Horizontal (SH) modes. Lamb and $\mathrm{SH}$ waves are extensively used for inspections of flat plates and tubes. In fact, it has been shown that the $L(0,1)$ and $L(0,2)$ modes correspond to the A0 Lamb mode and SO Lamb mode respectively, and so forth. Lamb and Shear Horizontal (SH) modes are usually exploited in the $250 \mathrm{kHz}-1$ $\mathrm{MHz}$ range. However, in view of the scope of this paper, existing problems in using cylindrical wave modes for corrosion inspection in pipes will be discussed.

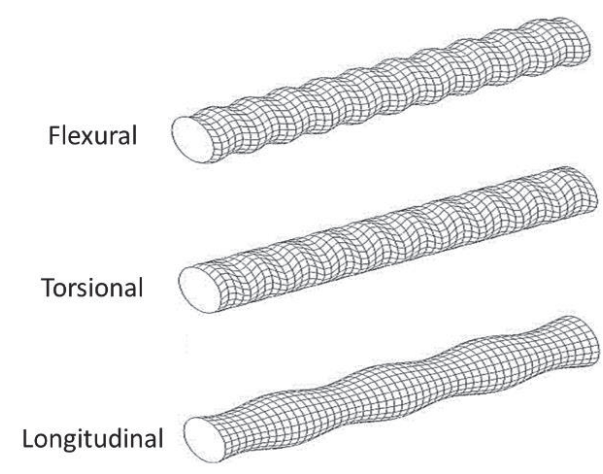

Figure 3 - Main Classes of GWs Existing in Hollow Cylindrical Waveguides

\section{Discussion}

\subsection{Dispersion Behavior}

The dispersive nature (dependence of group and phase velocities on frequency) of GWs makes it more challenging to use in corrosion inspection [34]. Dispersiveness causes amplitude decay of receipt signals because of the shape change of wavelets as it propagates along the pipe structure dissipates energy. Therefore, on a long-range test, it is advantageous to excite a mode in a nondispersive frequency region. By choosing a non-dispersive frequency range the amplitude of the signal can be retained. The $L(0,2)$ mode is non-dispersive over frequency ranges below $120 \mathrm{kHz}$ [35-37]. The T(0,1) mode is nondispersive across all frequencies [38]. Hence, the axially symmetric $L(0,2)$ and $T(0,1)$ modes are the most widely-used modes for pipelines. Sensitivities of these two modes to different defects vary. Longitudinal modes are unsuitable for detecting axial defects for which circumferential extents are thin. Torsional modes are mainly used to detect circumferential defects [39]. Torsional waves are preferred longitudinal waves in inspections as the wave energy does not leak into the fluids inside the pipe nor to the surrounding when the pipes are buried.

In LRUT, minimizing the signal attenuation is paramount. The signal strengths of the modes are highly dependent upon the position of the transducers at the ends of the pipes. To obtain the optimum signal amplitude at each frequency reading, transducers must be placed in the best possible arrangement. Niu et al. [40] have investigated the excitation of torsional $\mathrm{T}(0,1)$ mode by two different piezoelectric transducer set-ups. The same authors, in another investigation, have produced a transducer array arrangement to increase the wave power for a unidirectional $T(0,1)$ wave mode through waveform superposition [41]. Rose et al. [42] have demonstrated a technique to lower attenuation by truncating the total travel distance of the torsional GW reflections. In the study, Fiber Bragg Grating (FBG) optical fiber sensors were used to receive GW energy.

In a steel pipe, about $50 \mathrm{GW}$ modes can exist (Fig. 4). Commercial products are designed to generate a unique wave mode that propagates along the structure avoiding the creation of multimodal excitations. Nonetheless, with time the wall thickness due to corrosion can lead to the generation of unwanted wave modes. Consequently, the complexity of the analysis of the signals increases. Chang et al. [43] have replaced the conventional sparse deconvolution methods used for signal handling with an adaptive sparse deconvolution (ASD) method to make signal interpretation more efficient. Mahal et al. [44] have suggested a method to exploit the disparities in the power spectrum of the torsional wave and flexural waves, and to identify only the torsional waves which leads to the defect location. In another investigation, to improve the signal-to-noise ratio (SNR) Pedram et al. [45] have proposed a signal analyzing 
method using split-spectrum processing. The proposed method is expected to boost the SNR of torsional GWs by $30 \mathrm{~dB}$.

The use of a limited number of modes neglects the potential of the detection and analysis of complex defect profiles. Recent attempts have been made to investigate the feasibility of employing two or more wave modes for corrosion inspection in pipes. The use of other wave modes enables the detection of defects in a wide range of sizes, shapes, and orientations. Premesh et al. [46] have shown that the application of the $L(0,1)$ wave mode enhances the flaw sensitivity of approximately more than 2.5 times compared to the $T(0,1)$ wave mode and approximately 5 times compared to the $L(0,2)$ wave mode. Nurmalia et al. [47] based on their study has reported the sizing capabilities of $T(0,2)$ with regard to different defects. These results offer higher possibilities of using the $L(0,1)$ and $T(0,1)$ wave modes for ultrasonic GW inspection of pipelines. Taking a different approach Hayashi et al. [48] have developed an experimental system to visualize wall thinning patterns of an aluminum pipe. The system involves flexural elastic waves generated by lazers. Yeung et al. [49] have presented a crack model developed using spectral finite element method (SFEM) for defect analysis in pipes. The proposed for defect sizing model take both torsional and flexural motions into consideration.

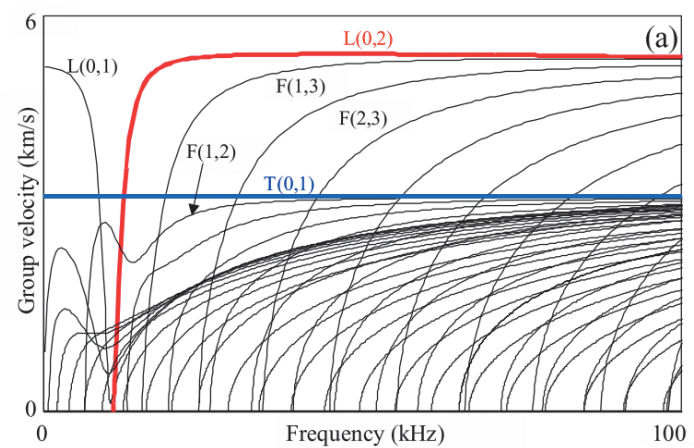

Figure 4 - Dispersion Curve for a 6-inch, Schedule 40 Steel Pipe[50]

\subsection{Complex Pipe Geometries}

Pipe bends pose difficulties in using GWs in corrosion inspection. As pipe bends are curved waveguides along and beyond them, wave mode conversion gets extreme, making signal interpretation more challenging [46-50]. The transmission and reflection coefficients of waves in bends depend on the pipe wall thickness, the bend radius, and the length of the bend [52] [53]. Thus, analytical equation development in pipe bends is difficult, and instead, numerical modeling techniques such as semi-analytical finite method [51], finite elements [52] [54] [55], and spectral element method [56] are used in investigations. In recent years, an extensive amount of work has been carried out concerning GW propagation in coated pipes. According to Luo et al. [54] in inspection, the defect detection sensitivity of $T(0,1)$ and $L(0,2)$ modes exceeds in extrados of the bend compared to the intrados. It is suggested the reason is that most of the energy of $T(0,1)$ mode or $L(0,2)$ mode focuses on the extrados of the pipe bend while little passes through intrados of the bend. Similar results have been obtained in an investigation by Heinlein et al. [55] when $T(0,1)$ mode was used for corrosion inspection on carbon steel pipe with comparable degrees of bend. The outcomes suggest that for circumferential cracks, the variance of the torsional GW inspection sensitivity around a bend fits the von Mises stress distribution. For small, approximately equivalent corrosion defects, a similar variation is expected.

\subsection{Pipe Coatings}

In order to minimize corrosion, metallic pipes are often covered with protective layers of either organic, metal, or non-metallic coatings. In the petroleum industry, most pipelines are covered with bitumen or epoxy-based materials (such as three-layer polyolefins (3LPO) and Fusion Bonded Epoxy (FBE)) as they have sufficient plasticity to resist detachment of the protective layer during temperature variations of the fluids [57]. The viscoelastic behavior of these coatings absorbs sound energy causing substantial damping in the propagating waves, thereby reducing the pipe length that can be examined from a given location of the transducer [58]. It is also reported that a thick elastic coating would introduce new modes, which are mainly confined to the coating layer and certain modes are unaffected by the elastic coating [59]. Several authors have reported the attenuation behavior of longitudinal wave modes, torsional wave modes [60] in steel pipelines under bitumen [35], and epoxy coatings [61] [62]. Huan et al. [61] have reported the attenuation levels of $T(0,1)$ waves propagating in buried steel pipes that are under six different types of coatings. The study also has compared the efficiency of d15 and d25 pitch-catch PZT rings under the given conditions. 


\subsection{Operating Temperature}

Many pipelines operate at high temperatures. However, the change of temperature will seriously affect the propagation of GW because of the temperature-dependent behavior of mechanical properties of materials, such as Young's modulus, Poisson's ratio, and density. Above $100{ }^{\circ} \mathrm{C}$ the corrosion rate in metallic pipelines accelerates due to a lack of effectiveness in corrosion protection methods [63] [64]. In high-temperature environments mechanical properties of material changes, attenuation increase. A considerable amount of work has been done to study the dispersion characteristics of GW modes used for pipe inspection [60] [65].

\section{Conclusions}

Corrosion in metallic pipelines induce defects that threaten the integrity of the pipeline systems. Ultrasonic GW techniques offer the possibility of rapid scanning approaches over extended lengths of metallic pipelines for corrosion and other defects. Currently, only two cylindrical GW modes, $L(0,2)$ and $T(0,1)$ are extensively used for defect detection in pipelines owing to the fact that they can be excited in a non-dispersive frequency region, which makes the waves get reflected or scattered from the defect less complex to analyze.

In practice, these wave modes are excited independently during pipework inspection. Single wave mode usage encounters four main challenges: signal attenuation, sizing multi axis defects, increasing flaw size sensitivity and processing dynamic signals. The paper identifies five factors (A-E) that pose these challenges. The first factor is intrinsic whereas the remaining four are extrinsic.
A. Wave displacement (direction/ wavelength)
B. Pipe coatings (bitumen/FBE)
C. Complex pipe geometries (numerous bends / branches)
D. Pipe content (deposits/high-viscosity fluids)
E. High operating temperature

In summary, Table 1 refers to all the combinations the challenges can be linked to, the factors induced them and options available to overcome these barriers.

Table 1 - Challenges in Using $\mathrm{L}(0,2)$ and $T(0,1)$ in Pipeline Inspection

\begin{tabular}{|c|c|c|c|c|c|c|}
\hline \multirow[t]{2}{*}{ Challenge encountered } & \multicolumn{5}{|c|}{$\begin{array}{l}\text { Factors induced the } \\
\text { challenge }\end{array}$} & \multirow[t]{2}{*}{ Available options to overcome the challenge } \\
\hline & A & B & C & D & $E$ & \\
\hline 1. Signal attenuation & & $\begin{array}{l}\checkmark \\
x\end{array}$ & $\begin{array}{l}\checkmark \\
x\end{array}$ & $\checkmark$ & & $\begin{array}{l}\text { - Excite the wave modes in a non- } \\
\text { dispersive frequency range } \\
\text { - Efficient transducer/sensor positioning } \\
\text { arrangements } \\
\text { - SNR boosting algorithms }\end{array}$ \\
\hline $\begin{array}{l}\text { 2. Sizing multi axis } \\
\text { defects }\end{array}$ & $\begin{array}{l}\sqrt{2} \\
x\end{array}$ & & & & & \multirow{2}{*}{ - Incorporating multiple wave modes } \\
\hline $\begin{array}{l}\text { 3. Increasing flaw size } \\
\text { sensitivity }\end{array}$ & $\begin{array}{l}x \\
x \\
\end{array}$ & & & & & \\
\hline $\begin{array}{l}\text { 4. Processing dynamic } \\
\text { signals }\end{array}$ & & & & & $\begin{array}{l}\sqrt{v} \\
x\end{array}$ & $\begin{array}{l}\text { - Design transducers that can withstand } \\
\text { high temperatures }\end{array}$ \\
\hline
\end{tabular}

** Note L $(0,2) \checkmark$

$\mathrm{T}(0,1) \times$

\section{Acknowledgment}

This research work was funded by the Senate Research Committee Grant - SRC/LT/17/24 offered by the University of Moratuwa.

\section{References}

1. Skovhus, T. L., Enning, D., \& Lee, J. S., Microbiologically influenced corrosion in the upstream oil and gas industry, Taylor \& Francis, CRC Press, September, 2017, 531 p.

2. Javaherdashti, R., Nwaoha, C., \& Tan, H., Corrosion and Materials in the Oil and Gas 
Industries, Taylor \& Francis, CRC Press, 2016 $684 \mathrm{p}$.

3. Askari, M., Aliofkhazraei, M., \& Afroukhteh, S., "A Comprehensive Review on Internal Corrosion and Cracking of Oil and Gas Pipelines," J. Nat. Gas Sci. Eng., Vol. 71, No. September 2018, pp. 102971.

ASTM G193-12d, "Standard Terminology and Acronyms Relating to Corrosion," ASTM Int, 2012

5. ASTM G40-15, "Standard Terminology realting to Wear and Erosion," ASTM Int., 2016.

6. Peiris, M. D. H. C., Perera, L. W. L., \& De Silva, G. I. P., "Study of the Effect of Sulphide Stress Corrosion on the Load Bearing Capability of API 5L Grade B Steel used in Petroleum Pipelines," Vol. LIII, No. 02, 2020, pp.13-21.

7. European Gas Pipeline Incident Data Group (EGIG), "10th Report of the European Gas Pipeline Incident Data Group (period 1970 2016)," No. March 2018, p. 50.

8. Petrovic, Z., "Catastrophes Caused by Corrosion," Vojnoteh. Glas., Vol. 64, No. 4, 2016, pp. 1048-1064.

9. Biezma, M. V., Andrés, M. A., Agudo, D., \& Briz, E., "Most Fatal Oil \& Gas Pipeline Accidents Through History: A Lessons Learned Approach," Eng. Fail. Anal., Vol. 110, 2020, p. 104446

10. Firestone, F. A., "Flaw detecting device and measuring instrument," United States Patent US2398701A,1942.

11. Vanaei, H. R., Eslami, A., \& Egbewande, A., "A Review on Pipeline Corrosion, In-Line Inspection (ILI), and Corrosion Growth Rate Models," Int. J. Press. Vessel. Pip., Vol. 149, 2017, pp. 43-54.

12. Gonzalez-Franchi, G., Leek, N., PalmerJones, R., \& Lewis, T., "Evaluation of the Reliability and Accuracy of MFL and UT ILI Tools for Detection of Pinhole Defects," Pipeline Pigging and Integrity Management Conf.(PPIM 2015), 2015.

13. Wang, H., Yajima, A., Liang, R. Y., \& Castaneda, H., "A Bayesian Model Framework for Calibrating Ultrasonic InLine Inspection Data and Estimating Actual External Corrosion Depth in Buried Pipeline Utilizing a Clustering Technique," Struct. Saf., 2015.
14. Tennakoon, A. I., Sivahar, V., Piyathilake, M., \& Metthananda, G., "Effect of Carbon Content on the Correlation between Ultrasonic Attenuation and Corrosion of Plain Carbon Steels," MERCon 2019 Proceedings, 5th Int. Multidiscip. Moratuwa Eng. Res. Conf., 2019, pp. 605-609.

15. Jayasooriya, E. D., Piyathilake, S. A. K. V. M., Sivahar, V., \& Munasinghe, R. G. N. S. D. S., "Effect of Penetration of Corrosion on the Load-Bearing Capacity of Mild Steel," MERCon 2018 - 4th Int. Multidiscip. Moratuwa Eng. Res. Conf., 2018, pp. 221-225.

16. Felice M. V. \& Fan, Z., "Sizing of Flaws using Ultrasonic Bulk Wave Testing: A Review," Ultrasonics, Vol. 88, No. March, 2018, pp. 2642 .

17. "3 Effective NDT Ultrasonic Pipeline \& Piping Inspection Methods | Zetec." [Online]. Available: https://www.zetec.com/blog/3-effectivendt-ultrasonic-pipeline-piping-inspectionmethods/. [Visited: 28-Sep-2020].

18. "UltraWave LRT | Olympus IMS." [Online]. Available: $\quad$ https://www.olympusims.com/en/ultrawave-lrt/. [Visited: 28Sep-2020].

19. “Guided Waves: Innerspec's UT Inspection Techniques." [Online]. Available: https://www.innerspec.com/knowledge/g uided-waves/. [Visited: 28-Sep-2020].

20. Nawfi, N. M., Sarusan, N., Piyathilake, S. A. V. M., Sivahar, V., \& Munasinghe, R. G. N. D. S., "Remote Estimation of Degree of Corrosion using Ultrasonic Pulse Echo Methods," MERCon 2018 - 4th Int. Multidiscip. Moratuwa Eng. Res. Conf., No. 1, 2018, pp. 312-317.

21. Payan, C., Abraham, O., \& Garnier, V., "Ultrasonic Methods," Non-destructive Test. Eval. Civ. Eng. Struct., 2018, pp. 21-85.

22. Shivaraj, K., Balasubramaniam, K., Krishnamurthy, C. V., \& Wadhwan, R., "Ultrasonic Circumferential Guided Wave for Pitting-Type Corrosion Imaging at Inaccessible Pipe-Support Locations," J. Press. Vessel Technol. Trans. ASME, Vol. 130, No. 2, 2008, pp. 0215021-12150211.

23. Cochran, S., "Piezoelectricity and Basic Configurations for Piezoelectric Ultrasonic Transducers," Ultrason. Transducers Mater. Des. Sensors, Actuators Med. Appl., 2012, pp. 3-35. 
24. Hirao, M., \& Ogi, H., Electromagnetic Acoustic Transducers: Noncontacting Ultrasonic Measurements using EMATs, 2nd Ed., Springer, 2017, 380 p.

25. Lacheisserie, E. du T., Magnetostriction: theory and applications of magnetoelasticity, CRC-Press, Boca Raton, Jun 9, 1993, 408 p.

26. Kwun, H., Hanley, J. J., \& A. E. Holt, "Detection of Corrosion in Pipe Using the Magnetostrictive Sensor Technique," in Proc.SPIE, 1995, Vol. 2459.

27. Kwun, H. \& Holt, A. E., "Feasibility of Under-Lagging Corrosion Detection in Steel Pipe Using The Magnetostrictive Sensor Technique," NDT E Int., Vol. 28, No. 4, 1995, pp. 211-214.

28. Gazis, D. C., “Three-Dimensional Investigation of the Propagation of Waves in Hollow Circular Cylinders. I. Analytical Foundation," J. Acoust. Soc. Am., Vol. 3, No. 1950, 1959.

29. Gazis, D. C., "Exact Analysis of the PlaneStrain Vibrations of Thick-Walled Hollow Cylinders," J. Acoust. Soc. Am., Vol. 30, No. 8, 1958, pp. 786-794.

30. Zemanek, J., "An Experimental and Theoretical Investigation of Elastic Wave Propagation in a Cylinder," J. Acoust. Soc. Am., Vol. 51, No. 1B, 1972, pp. 265-283.

31. Wang, T., Yang, C., Ye, L., Spray, D., \& Xiang, Y., "Evaluation of Guided Wave Propagation in Steel Pipes," Recent Adv. Struct. Integr. Anal. - Proc. Int. Congr., 2014, pp. 255-260.

32. Silk M. G., \& Bainton, K. F., "The Propagation in Metal Tubing of Ultrasonic Wave Modes Equivalent to Lamb Waves," Ultrasonics, 1979.

33. Nicholson N. C., \& McDicken, W. N., “Mode Propagation of Ultrasound in Hollow Waveguides," Ultrasonics, Vol. 29, No. 5, 1991, pp. 411-416,.

34. Rose, J. L., Ultrasonic guided waves in solid media, Cambridge University Press, July, 2014, 512 p.

35. Kirby, R., Zlatev, Z., \& Mudge, P., “On the Scattering of Longitudinal Elastic Waves from Axisymmetric Defects in Coated Pipes," J. Sound Vib., Vol. 332, No. 20, 2013, pp. 5040-5058.

36. Leinov, E., Lowe, M. J. S., \& Cawley, P., "Ultrasonic Isolation of Buried Pipes," J. Sound Vib., Vol. 363, pp. 225-239, 2016.
37. Alleyne D. N., \& Cawley, P.,“The Excitation of Lamb Waves in Pipes Using Dry-Coupled Piezoelectric Transducers," J. Nondestruct. Eval., Vol. 15, No. 1, 1996, pp. 11-20.

38. Liu, Z., He, C., Wu, B., Wang, X., \& Yang, S., "Circumferential and Longitudinal Defect Detection Using $\mathrm{T}(0,1)$ Mode Excited by Thickness Shear Mode Piezoelectric Elements," Ultrasonics, Vol. 44, No. SUPPL., 2006, pp. 1135-1138.

39. Carandente R., \& Cawley, P., "The Effect Of Complex Defect Profiles on the Reflection of the Fundamental Torsional Mode in Pipes," NDT E Int., Vol. 46, No. 1, 2012, pp. 41-47.

40. Niu, X., Duan, W., Chen, H. P., \& Marques, H. R., "Excitation and Propagation of Torsional $\mathrm{T}(0,1)$ Mode for Guided Wave Testing of Pipeline Integrity," Meas. J. Int. Meas. Confed., Vol. 131, 2019, pp. 341-348.

41. Niu, X., Tee, K. F., \& Marques, H. R., "Enhancement of Unidirectional Excitation of Guided Torsional T $(0,1)$ Mode by Linear Superposition of Multiple Rings of Transducers," Appl. Acoust., Vol. 168, 2020, p. 107411.

42. Rose, J. L., Philtron, J., Liu, G., Zhu, Y., \& Han, M., "A Hybrid Ultrasonic GuidedwaveFiber Optic System for Flaw Detection in Pipe," Appl. Sci., Vol. 8, No. 5, 2018.

43. Chang, Y., Zi, Y., Zhao, J., Yang, Z., He, W., \& Sun, H., "An Adaptive Sparse Deconvolution Method for Distinguishing the Overlapping Echoes of Ultrasonic Guided Waves for Pipeline Crack Inspection," Meas. Sci. Technol., Vol. 28, No. 3, 2017.

44. Mahal, H. N., Yang, K., \& Nandi, A. K., "Defect Detection using Power Spectrum Of Torsional Waves in Guided-Wave Inspection of Pipelines," Appl. Sci., Vol. 9, No. 7, 2019.

45. Pedram, S. K., Mudge, P., and Gan, T. H., "Enhancement of Ultrasonic Guided Wave Signals Using A Split-Spectrum Processing Method," Appl. Sci., Vol. 8, No. 10, 2018.

46. Lowe, P. S., Sanderson, R. M., Boulgouris, N. V., Haig, A. G., \& Balachandran, W., "Inspection of Cylindrical Structures Using the First Longitudinal Guided Wave Mode in Isolation for Higher Flaw Sensitivity," IEEE Sens. J., Vol. 16, No. 3, 2016, pp. 706-714.

47. Nurmalia, Nakamura, N., Ogi, H., \& Hirao, M., "EMAT Pipe Inspection Technique Using Higher Mode Torsional Guided Wave $\mathrm{T}(0,2)$," NDT E Int., Vol. 87, No. January, 2017, pp. 78-84. 
48. Hayashi, T., "Non-Contact Imaging of Pipe Thinning using Elastic Guided Waves Generated and Detected by Lasers," Int. J. Press. Vessel. Pip., Vol. 153, 2017, pp. 26-31.

49. Yeung, C., \& Ng, C. T., “Time-Domain Spectral Finite Element Method for Analysis of Torsional Guided Waves Scattering and Mode Conversion by Cracks in Pipes," Mech. Syst. Signal Process., Vol. 128, 2019, pp. 305317.

50. Cawley, P., Lowe, M. J. S., Alleyne, D. N., Pavlakovic, B., \& Wilcox, P., "Practical Long Range Guided Wave Testing: Applications to Pipes and Rail," Mater. Eval., Vol. 61, No. 1, 2003, pp. 66-74.

51. Hayashi, T., Kawashima, K., Sun, Z., \& Rose, J. L., "Guided Wave Propagation Mechanics across A Pipe Elbow," J. Press. Vessel Technol. Trans. ASME, Vol. 127, No. 3, 2005, pp. 322327.

52. Verma, B., Mishra, T. K., Balasubramaniam, and P. Rajagopal, K., "Interaction of LowFrequency Axisymmetric Ultrasonic Guided Waves with Bends in Pipes of Arbitrary Bend Angle and General Bend Radius," Ultrasonics, Vol. 54, No. 3, 2014, pp. 801-808.

53. Demma, A., Cawley, P., Lowe, M., \& Pavlakovic, B., "The Effect of Bends on the Propagation of Guided Waves in Pipes," J. Press. Vessel Technol. Trans. ASME, Vol. 127, No. 3, 2005, pp. 328-335.

54. sheng Luo, G., ping Tan, J., Wang, L., \& Xu, Y., "Defects Detection in Typical Positions of Bend Pipes Using Low-Frequency Ultrasonic Guided Wave," J. Cent. South Univ., Vol. 22, No. 10, 2015, pp. 3860-3867.

55. Heinlein, S., Cawley, P., \& Vogt, T. K., "Reflection of Torsional $\mathrm{T}(0,1)$ Guided Waves From Defects in Pipe Bends," NDT E Int., Vol. 93, No. September 2017, pp. 57-63.

56. Wang, Y., Hao, H., Zhu, X., \& Ou, J. "Spectral Element Modelling of Wave Propagation with Boundary and Structural Discontinuity Reflections," Adv. Struct. Eng., Vol. 15, No. 5, 2012, pp. 855-870.
57. Hagarová, M., Cervová, J., \& Jaš, F., "Selected Types of Corrosion Degradation of Pipelines," Koroze a Ochr. Mater., Vol. 59, No. 1, 2015, pp. 30-36.

58. Castaings, M., \& Bacon, C. "Finite Element Modeling of Torsional Wave Modes Along Pipes with Absorbing Materials," J. Acoust. Soc. Am., Vol. 119, No. 6, 2006, pp. 3741-3751.

59. Pan, E., Rogers, J., Datta, S. K., \& Shah, A. H., "Mode Selection of Guided Waves for Ultrasonic Inspection of Gas Pipelines with Thick Coating," Mech. Mater., Vol. 31, No. 3, 1999, pp. $165-174$.

60. Cobb, A. C., Kwun, H., Caseres, L., \& Janega G., "Torsional Guided Wave Attenuation in Piping from Coating, Temperature, and Large-Area Corrosion," NDT E Int., Vol. 47, 2012, pp. 163-170.

61. Huan, Q., Chen, M., \& Li, F., "Long-Distance Structural Health Monitoring of Buried Pipes Using Pitch-Catch $\mathrm{T}(0,1)$ Wave Piezoelectric Ring Array Transducers," Ultrasonics, Vol. 106, No. April, 2020, p. 106162.

62. Predoi M. V., \& Petre, C. C., “Thin Wall Pipe Ultrasonic Inspection through Paint Coating," Phys. Procedia, Vol. 70, 2015, pp. 287-291.

63. Obot, I. B. et al., "High Temperature Sweet Corrosion and Inhibition in the Oil and Gas Industry: Progress, Challenges and Future Perspectives," J. Pet. Sci. Eng., Vol. 185, February 2020, pp. 106469.

64. Kvarekval, J., Nyborg, R., \& Choi, H., "Formation Of Multilayer Iron Sulfide Films during High Temperature CO2/H2S Corrosion of Carbon Steel," Proc., NACE Int. Corrosion Conf. Series, Vol. 2003-April, 2003.

65. Leinov, E., et al., "Characteristics of HighTemperature Equipment Monitoring using Dry-Coupled Ultrasonic Waveguide Transducers," Ultrasonics, Vol. 108, No. 1, 2016, pp. 225-239. 